\title{
A study on the effect of organizational learning on organizational performance with an emphasis on dynamic capacity
}

\author{
Asal Ashtari $^{\mathrm{a}^{*}}$ and Jamshid Salehi-Sadaghiani ${ }^{\mathrm{b}}$
}

${ }^{a}$ M.Sc. Student, Department of Industrial Management, Allameh Tabataba'i University, Tehran, Iran ${ }^{b}$ Professor, Department of Industrial Management, Allameh Tabataba'i University, Tehran, Iran

\begin{tabular}{|c|c|}
\hline CHRON I C L E & ABSTRACT \\
\hline $\begin{array}{l}\text { Article history: } \\
\text { Received January 14, } 2014 \\
\text { Accepted } 10 \text { June 2014 } \\
\text { Available online } \\
\text { June } 142014 \\
\text { Keywords: } \\
\text { Organizational learning culture } \\
\text { Organizational performance } \\
\text { Dynamic capacity }\end{array}$ & $\begin{array}{l}\text { The present study examines the effect of organizational learning culture on organizational } \\
\text { performance by considering the role of dynamic capacity as a mediator in an Iranian bank } \\
\text { named Refah Bank. The study uses a questionnaire, which was originally developed by Hung et } \\
\text { al. (2010) [Hung, R. Y. Y., Yang, B., Lien, B. Y. H., McLean, G. N., \& Kuo, Y. M. (2010). } \\
\text { Dynamic capability: Impact of process alignment and organizational learning culture on } \\
\text { performance. Journal of World Business, 45(3), 285-294.] and examines different hypotheses } \\
\text { using SPSS software package with the help of LISREL method. The results show that } \\
\text { organizational learning culture and dynamic capacity positively influenced on organizational } \\
\text { performance. In addition, organizational learning culture had a significant positive effect on } \\
\text { dynamic capacity and dynamic capacity variable played the mediator role to the organizational } \\
\text { learning culture as well as organizational performance. }\end{array}$ \\
\hline
\end{tabular}

\section{Introduction}

Knowledge is a primary valuable resource for an organization's ability to innovate and to compete. Knowledge exists within the individual employees, and in a composite sense within the firms. Strategic assets are the essential determinants of a firm's capability to keep a sustainable competitive advantage. Bollinger and Smith (2001) combined the resource-based view theory with characteristics of knowledge to demonstrate that organizational knowledge is indeed a strategic asset. They explained practical considerations for implementation of knowledge management principles. Chand and Katou (2007) investigated whether some specific characteristics of hotels influence organizational performance in the hotel industry in India. The study also investigated whether some human resource management (HRM) systems could influence on organizational performance in the hotel industry in India. Their results indicated that hotel performance was positively associated with *Corresponding author.

E-mail addresses: res@faezirad.ir (M. Faezi-Rad) 
hotel category and kind of hotel. In addition, hotel performance was positively associated with the HRM systems of recruitment and selection, etc. Social capital is another important asset for forms. According to Chang et al. (2006), social capital is not significantly influenced with group dynamics or later with organizational innovativeness; yet, stronger social capital would bloom more organizational learning. Organizational learning is another component of any firm and there are many studies on development of the effects of various factors on this factor (Moores, 2010; Saffold, 1988). Vera and Crossan (2004), for instance, developed a theoretical model of the effect of CEO and top manager leadership styles and practices on organizational learning. Rhodes et al. (2008) presented an integrative model of organizational learning and social capital on effective knowledge transfer and perceived organizational performance.

\section{The proposed study}

The present study examines the effect organizational learning culture on organizational performance by considering the role of dynamic capacity as the mediator in an Iranian bank named Refah Bank. The study uses a questionnaire, which was originally developed by Hung et al. (2010) and analyze them using SPSS software package with the help of LISREL method. The sample size is calculated as follows,

$n=\frac{N \times z_{\alpha / 2}^{2} \times p \times q}{\varepsilon^{2} \times(N-1)+z_{\alpha / 2}^{2} \times p \times q}$,

where $N$ is the population size, $p=1-q$ represents the yes/no categories, $z_{\alpha / 2}$ is CDF of normal distribution and finally $\varepsilon$ is the error term. Since we have $p=0.5, z_{\alpha / 2}=1.96$ and $N=1490$, the number of sample size is calculated as $n=306$. Cronbach alpha is calculated as 0.933 , which is well above the minimum acceptable level of 0.70 . There are four hypotheses as follows,

1. Organizational learing culture influences positively on dynamic capacity.

2. Dynamic capacity influences positively on organizational performance.

3. Organizational learning culture influences positively on organizational performance.

4. Dynamic capacity plays a mediator role on relationship between organizational learning culture and organizational performance.

Fig. 1 demonstrates the structure of the proposed study. In addition, Fig. 2 shows personal charactersitics of the participants.

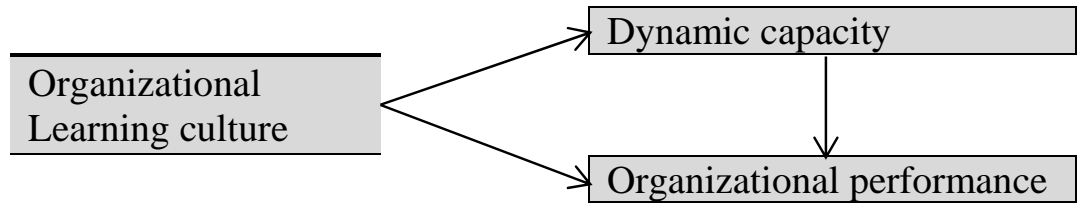

Fig. 1. The proposed study

The organizational learning culture consists of three levels of individual, team and organization. Dynamic capacity consists of three components including strategic, innovation and organizational management capacity. 


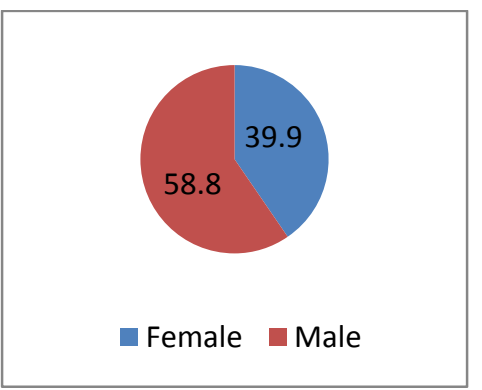

Gender

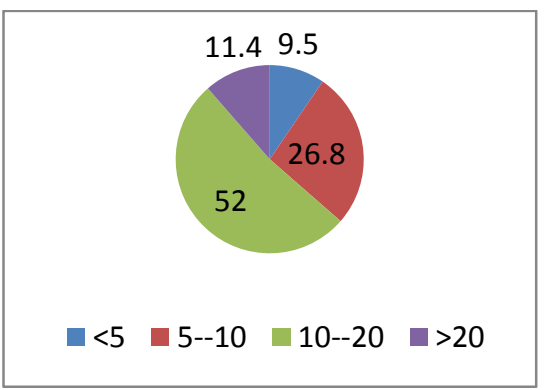

Job experience

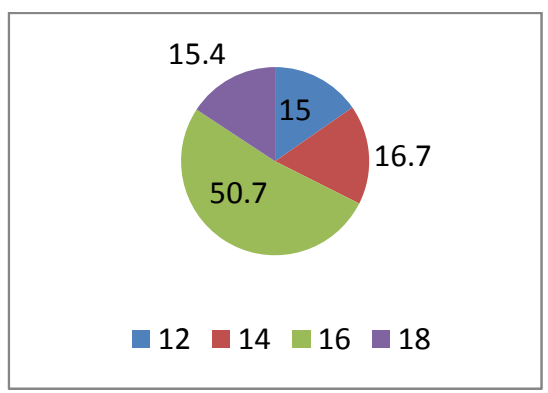

Years of education

Fig. 2. Personal characteristics of the participants

As we can observe from the results of Fig. 2, most participants were male with good educational background as well as job experiences.

\section{The results}

In this section, we present details of the implementation of the proposed model on testing four hypotheses of the survey. The study uses structural equation modeling to examine the hypotheses of the survey and Fig. 3 shows details of our results.

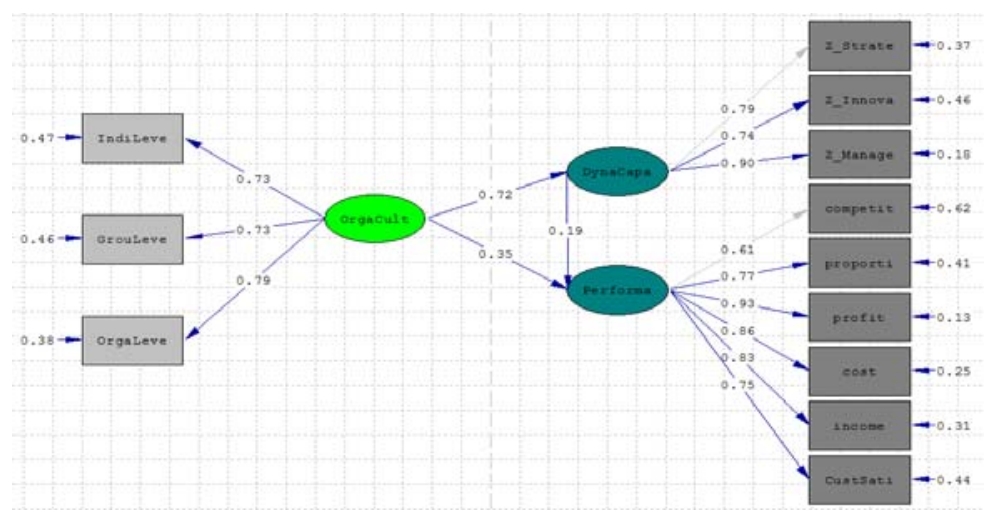

Fig. 3. The results of standard coefficients of the implementation of structural equation modeling

The results of the implementation of the proposed study have yielded some statistical observations summarized in Table 1 as follows,

Table 1

The summary of statistical observations

\begin{tabular}{lccc}
\hline Description & Statistics & Value & Desirable limit \\
\hline Chi-Square/degree of freedom & Chi-Square/df & 2.96 & Chi-Square/df $<3$ \\
Root mean square error of approximation & RMSEA & 0.00 & RMSEA $<0.09$ \\
Goodness of fit index & GFI & 0.92 & GFI $>0.9$ \\
Augmented Goodness of fit index & AGFI & 0.87 & AGFI $>0.85$ \\
Comparative fit index & CFI & 0.91 & CFI $>0.90$ \\
Incremental fit index & IFI & 0.91 & IFI $>0.90$ \\
\hline
\end{tabular}

As we can observe from the results of Table 1, all statistical observations are within desirable limits. Therefore, we can interpret the results of SEM. Table 2 shows details of the results of testing hypotheses of the survey. 
Table 2

The summary of testing four hypotheses

\begin{tabular}{lcccccc}
\hline Hypothesis & Value & Standard error & t-value & $\mathrm{R}^{2}$ & Sig. & Result \\
\hline First & 0.72 & 0.1 & 10.66 & 0.26 & $\mathrm{P}<0.01$ & Confirmed \\
Second & 0.19 & 0.096 & 2.00 & 0.26 & $\mathrm{P}<0.01$ & Confirmed \\
Third & 0.35 & 0.074 & 3.43 & 0.52 & $\mathrm{P}<0.01$ & Confirmed \\
Fourth & 0.14 & - & 21.32 & - & $\mathrm{P}<0.01$ & Confirmed \\
\hline
\end{tabular}

The results of Table 2 confirm all four hypotheses of the survey. In other words, organizational learing culture influences positively on dynamic capacity and Dynamic capacity influences positively on organizational performance. In addition, organizational learning culture influences positively on organizational performance and finally, dynamic capacity plays a mediator role on relationship between organizational learning culture and organizational performance.

\section{Conclusion}

In this paper, we have presented an empirical investigation to study the dynamic relationship between organizational learning culture and organizational performance. The study has accomplished in banking industry and the results have confirmed all four hypotheses of the survey. The results of our investigation are consistent with findings of Hung et al. (2010) in the literature.

\section{Acknowledgement}

The authors would like to thank the anonymous referees for constructive comments on earlier version of this paper. We would like to thank the officials of Reffah Bank for cordially cooperating in accomplishment of this survey.

\section{References}

Bollinger, A. S., \& Smith, R. D. (2001). Managing organizational knowledge as a strategic asset. Journal of knowledge management, 5(1), 8-18.

Chand, M., \& Katou, A. A. (2007). The impact of HRM practices on organisational performance in the Indian hotel industry. Employee Relations, 29(6), 576-594.

Chang, S. C., Chiang, C. Y., Chu, C. Y., \& Wang, Y. B. (2006). The Study of Social Capital, Organizational Learning, Innovativeness, Intellectual Capital, and Performance. The Journal of Human Resource and Adult Learning, 64-71.

Hung, R. Y. Y., Yang, B., Lien, B. Y. H., McLean, G. N., \& Kuo, Y. M. (2010). Dynamic capability: Impact of process alignment and organizational learning culture on performance. Journal of World Business, 45(3), 285-294.

Moores, T. T. (2010). Organizational performance under conditions of vulnerability: A multi-agent perspective. Expert Systems with Applications, 37(4), 3111-3117.

Rhodes, J., Lok, P., Hung, R. Y. Y., \& Fang, S. C. (2008). An integrative model of organizational learning and social capital on effective knowledge transfer and perceived organizational performance. Journal of workplace learning, 20(4), 245-258.

Saffold, G. S. (1988). Culture traits, strength, and organizational performance: Moving beyond “strong” culture. Academy of Management Review, 13(4), 546-558.

Vera, D., \& Crossan, M. (2004). Strategic leadership and organizational learning. Academy of Management Review, 29(2), 222-240. 